\title{
Regional métier definition: a comparative investigation of statistical methods using a workflow applied to international otter trawl fisheries in the North Sea
}

\author{
Nicolas Deporte ${ }^{1}$, Clara Ulrich ${ }^{2, *}$, Stéphanie Mahévas ${ }^{3}$, Sébastien Demanèche ${ }^{1}$ and François \\ Bastardie $^{2}$
}

\author{
1 Ifremer, Brest, RBE/STH, BP 70, 29280 Plouzané, France \\ 2 Technical University of Denmark, National Institute for Aquatic Resources (DTU Aqua), Charlottenlund Castle, \\ 2920 Charlottenlund, Denmark \\ ${ }^{3}$ Ifremer, Nantes, RBE/EMH, rue de l'ile d'Yeu, BP 21105, 44311 Nantes Cedex 03, France \\ *: Corresponding author : Clara Ulrich, tel: +45 21 157486; fax: +45 35 883333; email address : clu@aqua.dtu.dk
}

\begin{abstract}
:
The European Common Fisheries Policy recognizes the importance of accounting for heterogeneity in fishing practices, and métier-based sampling is now at the core of the EU Data Collection Framework. The implementation of such an approach would require Member States to agree on the standard regional métier definitions and on practical rules to categorize logbook records into métiers. Several alternative approaches have been used in the past to categorize landings profiles, but no consensus has yet emerged. A generic open-source workflow is developed to test and compare a selection of methods, including principal components analysis (PCA), hierarchical agglomerative clustering (HAC), $K$-means, and Clustering LARge Applications (CLARA), and to provide simple allocation rules. This workflow is applied to a unique regional dataset consisting of bottom-trawl logbooks of five North Sea countries. No method proved to be infallible, but combining PCA with either CLARA or HAC performed best. For 2008, a hierarchical classification with 14 species assemblages is proposed. Discriminant analysis proved more robust than simple ordination methods for allocating a new logbook record into an existing métier. The whole approach is directly operational and could contribute to defining more objective and consistent métiers across European fisheries.
\end{abstract}

Keywords: cluster, Data Collection Framework (DCF), logbooks, metier, mixed fisheries, multivariate analysis, North Sea 


\section{Introduction}

The European Common Fisheries Policy (CFP) calls for the implementation of an ecosystem-based approach to fisheries management, with increasing focus on limiting the impact of fisheries' impact on the environment. As part of the process, the CFP recognizes the importance of accounting for heterogeneity in fishing practices, and the 2011 Proposal for the Reform of the CFP shows an obvious will to move away from single-stock and toward fleet-based management (EC, 2011). Some steps have already been taken in this direction over the last decade through e.g. differential effort reductions based on gear and mesh size categories, and the development of mixed-fisheries scientific advice (ICES, 2010). Analysing catch and effort by fishing activity allows more accurate estimates of partial fishing mortality induced by the various fleets. To make this approach operational, the first step is the definition of fishing activities. This topic is not new, and since the seminal work of Laurec et al. (1991), classifying fishing activities has been much investigated by the scientific community (see references below). The definition of homogeneous groups of fishing operations and/or fishing vessels is intended to characterize the overall fishing activity into a few, easy-to-manage categories. However, in spite of many years of scientific studies, no single and fully unified approach has yet emerged. Various criteria and scales can be used, which lead to different perceptions of the same reality (Ulrich et al., 2009). Nonetheless, the establishment of the European Data Collection Framework (DCF; EC, 2008) has been an important step forward, not least because it has led to agreement on the basic concepts and terminology. The DCF has adopted the definition that we follow here: A métier is a group of fishing operations targeting a specific assemblage of species, using a specific gear, during a precise period of the year and/or within the specific area.

The DCF defines métiers according to a hierarchical structure using six nested levels: Level 1- Activity (fishing/non fishing), Level 2- Gear class (e.g. trawls, dredges), Level 3Gear group (e.g. bottom trawls, pelagic trawls), Level 4- Gear type (e.g. Bottom otter trawl, Bottom pair trawl), Level 5- Target assemblage based on main species type (e.g. Demersal fish vs. Crustaceans or Cephalopods), Level 6- Mesh size and other selective devices. For convenience, we also define here a further disaggregation level distinguishing targets at the true species level (e.g. cod, haddock) as Level 7, as distinct from the DCF Level 5 which deals only with species type. This level 7 is expected to describe more accurately the actual landings profile. It must be noted that our use of the level 7 concept here may differ slightly from current usage at the national level in some cases.

To make these definitions operational Europe-wide, it is important that all coastal EU Member States agree at the regional scale on i) métier definitions at Levels 7 and 5 and ii) practical rules to allocate their own activities to métiers. Logbook data are the main source of information on the fishing activities. They detail for each trip of each vessel the amount of the main species caught and kept on board per catch day, location and type of gear used. Categorizing logbook data into Levels 1-4 (and to a lesser extent Level 6, depending of the accuracy of mesh size reporting) is straightforward because the required information is directly available in the logbooks. Categorization into Levels 5 and 7 , however, is more difficult because in the EU fishers do not have to declare which species they are actually targeting when fishing. Therefore the matching métier has to be inferred. ICES (2003) provided general concepts and ideas to define these métiers, but did not provide quantitative guidelines. Neither did the experts groups (EC, 2005; 2006) that led to the DCF. However, a number of analyses have been conducted at the national scale, and many approaches have been used. The earliest and simplest approach consists in selecting the fishing trips where a certain catch-proportion of selected key species is exceeded (e.g. Biseau, 1998, Ulrich et al., 2001). This approach is based largely on trialand-error, and often requires a qualitative, a priori, knowledge of the fisheries. Another approach consists of conducting multivariate analyses on the species composition in 
catch data by trip or fishing operation (referred to as catch or landings profiles), then grouping similar profiles into métiers. This grouping can be performed by direct visual inspection (Biseau and Gondeaux, 1988; Laurec et al., 1991) or statistically through cluster analysis. Within this approach, several statistical methods, settings and software have been used, and many local applications have been published in the literature, also in response to the requirements of DCF implementation. Rogers and Pikitch (1992) used two opposite types of hierarchical clustering techniques and Detrended Correspondence Analysis to define groundfish assemblages in Oregon and Washington waters. Lewy and Vinther (1994) used a Hierarchical Agglomerative Cluster analysis (HAC) when identifying Danish North Sea trawl fisheries, and a similar approach was later used by Holley and Marchal (2004) and Marchal (2008) on French fisheries; by Tzanatos et al. (2005) in Greece and by Jímenez et al. (2004) in Spain. He et al. (1997), Silva et al. (2002) and Bastardie et al. (2010) used K-means clustering approaches for fisheries in Hawaii, Spain and Denmark respectively. Pelletier and Ferraris (2000) combined Principal Component Analysis (PCA) and HAC to identify métiers of both an artisanal Senegalese fishery and French Celtic Sea fisheries, a sequence of methods which has been much used in subsequent studies (e.g. Ulrich and Andersen, 2004; Tzanatos et al., 2006, Campos et al., 2007; Katsanevakis et al., 2010). Finally, non-hierarchical clustering methods were used for classifying métiers in the Iberian peninsula, with Partition Around Medoids (PAM) used for Portuguese purse seine fisheries (Duarte et al., 2009) and its variant, Clustering LARge Applications (CLARA), used for Spanish otter trawl fisheries (Punzón et al., 2010, Castro et al., 2010, 2011).

Reviewing these numerous studies raises a number of questions. First, although mostly statistical, clustering has generally included an element of subjective choice, and the robustness of the results to these choices is unknown. Second, while the DCF aims at unifying métier definitions at the regional scale (i.e. across nations operating in the same region), all analyses described above were performed at national level involving limited datasets. The requirement for regional métiers is likely to provide different results by combining different fishing strategies across different member states, and may potentially also raise computational challenges due to larger datasets. Finally, all studies were performed on historical data aggregated over given periods of time (generally per year) but did not usually address the requirement to assign future logbook records to a métier as would be useful for real-time monitoring of fisheries.

To address these issues we have developed an operational framework that will allow i) the analysis of the sensitivity of métier definition (at Level 7) to the classification method; ii) linking the métier obtained at Level 7 to the target assemblage at Level 5; and iii) categorizing any new logbook records into the most relevant métier class. We stress that in the present work, we focus solely on Level 7 as a way to enhance and operationalize Level 5, and thus disregard Level 6. While DCF Levels 1-5 were defined at the whole European level and meant to be generically available, Level 6 was defined regionally and is not available in all regions. Therefore the methods described below deal only with analysis of landings profiles but not with their linkages with mesh size, as was attempted by e.g. Pelletier and Ferraris (2000), Ulrich and Andersen (2004) and Marchal (2008).

The application of the whole procedure is illustrated with the example of the international bottom otter trawl (OTB) fishery using combined logbook data from the main countries (Denmark, England, France, Scotland and the Netherlands) fishing in the North Sea region, i.e. ICES Subarea IV (North Sea), Division IIIaN (Skagerrak) and Division VIId (Eastern Channel). According to ICES (2010), the bottom trawling component of these nations together account for around half of the total landings of the main assessed species (cod, haddock, whiting, saithe, sole, plaice and Nephrops) in the North Sea. This study represents the first attempt to merge national logbook data into a regional dataset, hence in addition to its generic statistical scope, it also represents a major insight in to the nature of North Sea demersal trawl fisheries 


\section{Material and methods}

The workflow was developed entirely in R (R Development Core Team, 2010). The code associated with this present work is included in the "vmstools" R package (http://code.google.com/p/vmstools/) which is a library of tools for fishery data-related analyses (Beare et al., 2011, Hintzen et al., in press). Some R-specific extension packages were also used (FactoMineR, cluster, SOAR, amap, MASS, mda).

\section{DATA}

The dataset included detailed 2007-2008 logbook data for bottom otter trawl (OTB) fishing in ICES Subarea IV (North Sea), Division IIla (Skagerrak-Kattegat) and Division VIId (Eastern Channel). Logbooks is used here in its broad sense implying a merging of the actual logbooks filled-in by fishing vessels, with cash value information coming mainly from sales slips, and information on the fishing vessel coming from the fleet register, so that complete information is available for each fishing trip (Hintzen et al., in press.). In EU, a logbook must be filled for each fishery sequence, i.e. for each combination of fishing day, gear, mesh size and ICES rectangle. However, in practice, national fisheries research institutes do not all have access to the same level of disaggregation. For some, data are available down to the fishing operation (haul by haul information) while for some others, all operations of a given fishing trip are aggregated into one single record, with only the main area fished and gear used being indicated. The best information available for each country was retained, and the generic term logbook event (LE) was used to refer to each observation. This implies that for the countries whose available information was disaggregated to the fishing operation or day, a single fishing trip could eventually be characterised by one or several métiers. 74,712 LE were recorded for 2007 , and 96,758 for 2008 (the initial number of LE in 2008 was 98,017, but $1.3 \%$ of LE had some missing value information and were removed). The exchange format used throughout the study was the standardised EFLALO format, previously used in a number of research projects (e.g. Marchal, 2006, Beare et al., 2011). In this format, each row represents a LE, and columns include several descriptors (vessel, gear, mesh size, ICES rectangle, etc.), as well as weight and value of landings by species. ICES (2003) recommended that métiers be preferably defined on landings composition expressed in cash value if available, as this may reflect more accurately the actual targeting choices of the fishers. This option was retained here. The number of species recorded varied significantly between countries, from 49 (in Scotland) to 220 (in France), and when pooled together the whole dataset included 278 species in 2007 and 296 in 2008.

In 2008 , the ten main species ( $72 \%$ of the total value) landed by bottom trawls in the North Sea region were, in decreasing importance, Nephrops (NEP), sandeels (SAN), saithe (POK), Atlantic cod (COD), monkfish (MON), European plaice (PLE), haddock (HAD), herring (HER), whiting (WHG), and mackerel (MAC). But these species were not equally spread across all LE, as they were present in, respectively, 47, 3, 22, 42, 27, 46, 30, 4, 32 , and 11 percent of all LE. This reflects that some species are more heavily fished in dedicated métiers, often associated with specific countries, thus illustrating the need to collate data at the supra-national level.

\section{METHODS}

The comparison of methods for the characterisation and classification of landings profiles was performed through a number of sequential steps, as follows (Figure 1):

Step 1: identification of the important species out of all species recorded and the reduction of the dataset to these key species only. 
Step 2: investigation of the added value of initially running a PCA on the dataset to build preliminary groups of species.

Step 3: running a selection of clustering methods and settings, and characterizing the species-based Level 7 classifications obtained.

Step 4: relating the species-based Level 7 classifications to corresponding DCF Level 5 classifications

Step 5: predicting the classification of any new LE into the defined métiers. Each step is described below.

\section{STEP 1 - IDENTIFICATION OF MAIN SPECIES}

Let us denote $D^{0}$ the initial dataset, $D^{0}=\left(D_{i, j}^{0}\right)_{i=1, \ldots, n, j=1, \ldots, m}$ where $n$ stands for the number of LE, $m$ the number of species and $D_{i, j}^{0}$ is the landings in value of species $j$ during the $i$ th LE. A number of approaches were suggested for identifying key species out of the large dataset $D^{0}$. An objective method was to use a HAC on the species observations, i.e. on the transposed data set (all species x LE). More subjectively, main species could also be defined as the ranked list of species accumulating to a given percentage of the total catches (the perTotal method), or as the species representing at least a given percentage of at least one LE, i.e. species likely to represent a true target for part of the fishery (the perLogevent method). The three methods were thus implemented and compared.

In the HAC method, groups of species were identified by iterative pairwise agglomerations of elements based on the Ward minimum variance criterion (Ward 1963). The analysis was carried out on landings proportion by LE (landings profile) rather than on absolute values in order to be independent of LE size. We used a Scree test (Cattell 1966) for selecting the cut height of the dendrogram. The Scree test cuts the dendrogram at the successive largest gain in clustering variance ratio (Variance between clusters / Total variance of the dataset). This first run isolated a number of principal species and pooled the remaining species of lesser importance in a group of residual species. As this step generally isolated only few main species, similar HACs were subsequently run through a loop on the residual group, and each new species isolated by a monospecific cluster was added to the list. The loop stopped when all clusters contained more than one species. In the perTotal method, the percentage threshold was increased in steps of $5 \%$ from $5 \%$ to $100 \%$, and the ranked species summing up to this value was recorded. In the perLogevent method (working on landings profiles), the percentage threshold was decremented in steps of $5 \%$ from $100 \%$ to $5 \%$, and all species representing at least this value in at least one LE were recorded.

This approach allowed the exploration of the variability and the sensitivity of the definition of key species to differences in concepts and subjective thresholds, and the derivation of a robust list of species using a combination of outcomes from the three methods. Subsequently, the initial dataset (landings by LE x All species) was then transformed into landings profiles and reduced to the principal species only (LE $\times$ Principal species), denoted $D^{1}=\left(D_{i, j}^{1}\right)_{i=1, \ldots, n ; j=1, \ldots, p}$ where $p$ is the number of principal species $(p<=m)$ and $D_{i, j}^{1}=D_{i, j}^{0} / \sum_{j=1}^{m} D_{i, j}^{0}$.

After that step and based on this conveniently reduced number of species, national differences observed in the coding of unsorted mixed groups of cuttlefish, squids, monkfish, skates and rays were made consistent to avoid potential bias in the results. 


\section{STEP 2 - PCA TRANSFORMATION}

Most of the studies cited above made use of a PCA prior to the actual clustering, and it was therefore decided to investigate the relevance of this choice. There are two reasons for applying a PCA. First, it helps reducing the multi-dimensional catch matrix to a smaller number of informative components represented by the first $n$ axes of the PCA transformation. Second, it is informative about the interactions among species across LE. When running a PCA, it is necessary to specify the number of axes to be retained. Two possible criteria were implemented (Hartigan, 1975): 1) using a second-order Catell Scree test looking for the significant marginal increases of explained inertia, and 2) selecting all axes accumulating 70 percent of the explained inertia. The resulting dataset is the matrix of new LE coordinates using the retained axes of the PCA, $D^{2}=\left(D_{i, j}^{2}\right)_{i=1, \ldots, n, j=1, \ldots, k}$ where $k$ is the number of retained axes $(k<=p)$ and $D_{i, j}^{2}$ is the coordinate of the ith LE on the $j$ th axis of the PCA.

\section{STEP 3 - CLUSTERING}

Let us denote $D^{3}$ the input dataset of the clustering step of the analysis. $D^{3}=D^{2}$ if a PCA was previously used, otherwise $D^{3}=D^{1}$. Three clustering methods were selected and implemented to be applied on $\left.D^{3}: 1\right)$ Hierarchical Agglomerative Classification (HAC) (Hartigan, 1975), 2) K-means, (Hartigan and Wong, 1979), and 3) Clustering LARge Applications (CLARA) (Kaufman and Rousseeuw, 1990). All methods lead to a classification of all individual LE, but they are based on different approaches and algorithms.

The HAC method initially assigns each LE to its own cluster and then the algorithm proceeds iteratively, at each stage joining the two most similar clusters, until there is just one single cluster. The similarity is computed using a distance function (default set to Euclidean distance) and a clustering method (default set to Ward criterion). The number of clusters is determined afterwards, once all combinations have been calculated, by using a Scree test, which can return successive thresholds for increasing number of clusters.

The two other methods assume that the final number of clusters is known a priori and set at $K$. In contrast to the HAC, these methods select first $K$ LE and assign them to their own clusters (kernels), and subsequently assign each LE of the dataset to the closest cluster, according to a similarity criteria (default set to the Euclidean distance).

With the K-means method, each cluster is characterized by its gravity centre (i.e. an average virtual LE) and the method is applied to the whole LE dataset (no sampling). For each new observation, the gravity centre of the cluster and the distances to the next LE are recalculated. The procedure is repeated with increasing values for $K$, and the most appropriate number of clusters can be selected by detecting the largest marginal losses of inertia between two consecutive numbers of clusters, similar to the HAC Scree test.

The CLARA method was developed to cope with large datasets. Subsets of the data, of user-defined number and size, are sampled and clustered using the Partitioning Around Medoids (PAM, Kaufman and Rousseeuw, 1987) algorithm. With this approach, the centre of the cluster is defined as the medoid, i.e. the most central LE which shows the smallest dissimilarity with other LE within the cluster. Identifying the medoid requires computing all dissimilarities within the cluster and comparing it with the sum of dissimilarities if any other LE in the cluster had been the medoid. The medoid is then adjusted accordingly, until convergence of the procedure. As in $\mathrm{K}$-means, the procedure is run with increasing values of $K$, and the most appropriate number of clusters is detected using the local maximum values of the silhouette of the classification. The silhouette provides an average comparison of the distance between a LE and the other LEs from its cluster, and between the same LE and the other LEs of the nearest cluster. Afterwards, all remaining LEs are 
assigned to their nearest medoid, using a user-defined method for calculating distances (default set to the Euclidean distance).

Regardless of the clustering method used, step 3 leads to a new matrix $D_{\text {ClusteringMethod }}^{4, \text { métiers }}=\left(D_{\text {ClusteringMethod }}^{4, \text { métiers }_{i, j}}\right)_{i=1, \ldots, n, j=1, \ldots, m+1}$ equal to $D^{0}$ with an additional column containing the result of the classification as an identifier of the cluster associated with each LE.

In order to perform a rigorous comparison of the performance and outcomes of the three clustering methods, an objective analysis plan was established. First, since the HAC method initially proved to be fairly computer-demanding and not straightforward to implement in $\mathrm{R}$ for the whole dataset, the approach was modified along the principles of the CLARA procedure, i.e. the HAC was performed on a sample of randomly selected LE representing a given percentage of all initial LE. The remaining LE were subsequently allocated to the defined clusters using linear discriminant analysis. As for CLARA, to avoid issues linked to the random sampling of LE, the procedure was set to be repeated a number of times, and the best classification with regards to maximising clustering variance ratio was retained for the final outputs.

The comparison between HAC and CLARA was done on the basis of five samples within each method, and with sample size set at $1 \%, 5 \%, 10 \%$ or $30 \%$ of the whole dataset. Since the sampling algorithm is performed internally within each method, the sampled datasets may differ in both methods, but since both methods proceed with multiple samples, they should ideally be robust to the sampling bias. Monitoring this robustness is exactly the purpose of the second test we performed as described below.

The second test follows from the observation that combining national logbook data resulted in a stratified dataset with rows intrinsically grouped by country and season, which affected the row sampling of HAC and CLARA. For this reason, we tested the robustness and the stability of the three methods by applying them to three permutations of the whole data set, where the LE lines were randomly shuffled before the analyses.

Thirdly, the three methods build on finding best performance of given criteria across consecutive number of clusters, but several thresholds can be observed when increasing the number of clusters. A first threshold is expected to distinguish the most well-defined fisheries (e.g., sandeel, Northern prawn) from the bulk of more mixed operations, while a second threshold is expected to return a more accurate description of these mixed fisheries. Therefore, two classifications were investigated for each method, returning both the first and the second threshold encountered with increasing numbers of clusters (an initial threshold could sometimes be observed for low numbers of clusters but was disregarded), corresponding to second and third Scree test minima for HAC; first and second largest inertia losses for K-means, and first and second silhouette maxima for CLARA respectively.

Ultimately, the most appropriate approach was selected on the basis of multiple considerations, i.e.:

1) the computational cost and data limitations (on a Linux server),

2) the clustering variance ratio,

3 ) the stability of results across different permutations of the initial dataset (shuffles),

4) the projections of LE by cluster on first factorial axes, with clusters expected to be well distinguished by axes and LE to be well grouped together,

5) some characteristics of the outcomes:

i) the final number of clusters, 
ii) the number of LE by cluster,

the list of characteristic species by cluster, representing both the main species in value and the most representative species caught in the cluster. Empirical rules were defined. Characteristic species should appear in the ranked list accumulating $75 \%$ of average value of the cluster, should be characterized by a test-value (a statistical metric comparing the proportion of that species in the landings of the cluster with the average proportion of the same species in the whole dataset, Lebart et al., 1995) over 50, and should appear in at least $30 \%$ of LE in the cluster.

6) the meaning and the relevance of clusters. This criterion is mainly based on expert knowledge. Experts played an important role in judging the validity of some métier definitions, for example if a cluster gathered two important species known for not being caught together, or if small but very specific fisheries could be identified, or if two clusters seemed redundant.

At the end of this step we selected one single clustering approach, with $D^{4, l e v e l 7-m e ́ t i e r s}$ denoting the resulting outcome. Each métier at Level 7 was named using the combination of gear used and the list of characteristic species.

\section{STEP 4 - LINKAGE WITH DCF LEVEL 5}

The DCF (EC, 2008) currently uses the métier definition at Level 5, based on species assemblage. For the OTB gear in the North Sea region, the DCF recognises in principle the existence of the mixed assemblages crustaceans-demersal fish (MCD) and cephalopods-demersal fish (MCF). However, it is also specified that "The target assemblage that comes up at the first position should be considered as the target assemblage to be reported in the matrix" (EC, 2008), which in practice would imply that only one type is defined, and not a mix. The notion of "first position assemblage" can be interpreted in different ways, and in the absence of clear quantitative guidelines, different national fisheries laboratories may have implemented different sets of simple empirical rules (referred to as "ordination rules"), for example:

- "First Species" method: identifying the single most abundant species in the LE and allocating the LE to the corresponding Level 5 assemblage of this species;

- "First Group" method: summing catch of the LE within the respective species types and allocating the LE to the most important Level 5 assemblage of the LE.

Assuming that Level 7 is a more accurate representation of fishing activities, we used this as a baseline to assess the validity of these ordination rules, by calculating the degree of correspondence between both. We first applied the two ordination rules directly to each LE of the initial dataset $D^{0}$ on its own catch profile. Second, we considered the list of characteristic species, as defined above, of each LE at its Level 7 cluster using $D^{4, \text { level7-métiers }}$, and related these to their corresponding assemblage, thus allowing the appearance of mixed assemblages at Level 5. Finally, we measured the contingency 
of both classifications in terms of number of LE in each Level 5. Obviously, for the clusters dominated by one single species, both classifications would be in broad agreement, but this may be less clear for clusters defined by more than one main species.

\section{STEP 5 - PREDICTION OF THE MÉTIER OF A NEW LE}

Métiers are not only used to characterize a fishery from historical data, but also to improve sampling monitoring and fishing mortality estimates. Some quantitative rules are therefore necessary to identify the most representative métier of any new LE (for example during the current year, before all annual data have been collected and new analyses can be run). Discriminant analysis is an efficient technique for deriving such quantitative allocation rules. It allows classifying a set of observations into predefined clusters, fitting a multi-choice model using one linear function for each cluster. This model is expected to predict the cluster of a LE based on a set of predictors, here the landings per species: given a new LE, all the $K$ discriminant functions ( $K$ being the number of clusters) are evaluated and the observation is assigned to class $i$ if the $i$ th discriminant function has the highest value. This analysis is performed using the matrix $D^{4, \text { level7-métiers }}$ corresponding to a set of observations for which the clusters are known.

\section{Results}

The detailed comparison of methods was performed on the largest and most recent dataset, i.e. 2008. Subsequently, the selected method was applied on the 2007 dataset, on which the discriminant analysis was also fitted. Finally, the results obtained for 2008 were compared with the predicted métiers using such allocation rules.

\section{STEP 1}

The HAC method retained 31 main species out of the 296 of the initial dataset (Figure 2). The perTotal method was more selective: given the strong dominance of very few species in the total value of the dataset, the incremental slope was very low, and 26 species represented $95 \%$ of the total value. The perLogevent method returned the largest range of species, with 60 species representing 100\% of the value of at least one LE. Combining these three sets of species and harmonising a few national codes led to a reduced dataset comprising 58 main species, representing $99.1 \%$ of the total value (Table 1).

\section{STEP 2}

The PCA showed some species clustering over the first axes (Figure 3). But little information was conveyed by each axis, and it was necessary to retain 36 axes to reach the threshold of $70 \%$ inertia. The Scree test was considered to keep too little information, as it retained only 9 axes cumulating $24.4 \%$ of the inertia. Therefore, the following analyses were performed on the 36 principal components, thus decreasing by $40 \%$ the number of columns used for clustering. 


\section{STEP 3}

The comparative analysis underlined large differences in the performance of the various methods and settings used (Table 2).

The K-means method was the fastest to compute, did not return any dataset size limitations, and had also higher variance ratios. However, its outcomes seemed largely unreliable and difficult to interpret. The number and characterisation of clusters was unstable across the three shuffles, and the method seemed to emphasize minor clusters (e.g. edible crab, Sebastes sp.) while pooling together most of the important species. On this basis, the K-means method was not considered appropriate and was not analysed further.

After implementation of the sampling procedure, the HAC method computed smoothly, even with large sample size. At 30\%, the method consistently returned eight clusters, with a variance ratio around $20 \%$, at first threshold classification. However, these were not completely consistent across the three shuffled datasets, with small differences observed in the characteristic species. More problematically, the method did not reach consistency at the second threshold, returning 9 to 12 clusters for the different shuffles.

The CLARA method turned out to be slowest to compute even with smaller sample size, and could not run with a $30 \%$ sample size. However, six consistent clusters were obtained across shuffles at $10 \%$ sampling size at the first threshold. At the second threshold, different numbers of clusters were also returned, explaining around $30 \%$ of the inertia. These clusters were meaningful and broadly consistent in terms of characteristic species, the additional clusters obtained being characterised by fisheries with few LE such as Norway pout or herring (usually little caught with OTB), and which could therefore have been missed by the sampling.

A closer comparison of the HAC and CLARA results obtained with the second shuffle indicated some degree of consistency (Table 3 and Figure 4). At the first threshold, six meaningful clusters were identified in common by both methods; three largely dominated by one single species (sandeel, Nephrops, sole), and three of mixed nature (a gadoidmonkfish, a squid-mullet-cuttlefish-whiting, and a plaice-lemon sole). In addition, HAC, unlike CLARA, identified two additional single-species fisheries, the common shrimp and the Northern prawn. Both classifications appeared relevant although the additional HAC clusters were preferred. At the second threshold, some large clusters were cut into smaller ones, providing a finer description of the mixed groups. There was again a high degree of similarity between outcomes of both methods; however, while most clusters appeared meaningful, HAC also returned some inconsistent results, pooling Norway pout and herring as characteristic of the same cluster when these two species are not routinely caught together.

All considered, it did not appear very obvious that one method performed significantly better than the other. Results were quite robust at the first threshold. But neither of the two methods proved infallible and fully robust to sampling size and row shuffling when investigating more precise definitions at the second threshold. At that threshold, however, the results provided by HAC seemed slightly less consistent; the variance ratio was lower and the clusters more overlapping on the first factorial axes (Figure 4). Therefore we chose to pursue the analyses with the results obtained with CLARA, with 10\% sample size and at the second threshold, as the baseline classification for illustration (Figure 5).

\section{STEP 4}

The results above were used as the basis for evaluating the accuracy of simple ordination rules allowing the allocation of a logbook event to a DCF Level 5 (Table 4).

The simple métiers (DEF, CRU) were generally well captured by the rules (around $95 \%$ of overlap), but obviously, these simple approaches could not capture clusters with mixed 
target type. For example, our clusters 3 and 7 were both dominated by a different combination of cephalopods and demersal fish (MCF), with species being very characteristic of the cluster (high test-value) and a large degree of co-occurrence (observed in more than $80 \%$ of the LE of the cluster). However, LE in these clusters were split in two distinct Level 5 categories with the ordination rules depending on the dominating species; $43 \%$ of them being considered as DEF and $52 \%$ as CEP with the "First Species" method, and 59\% and 38\% respectively with the "First Group" method.

Both ordination methods were generally in broad agreement with each other. However, the "First Group" method tended to favour the demersal fish métier (DEF), because of the large number of species belonging to this group. As a consequence, some LE would be classified as DEF, in spite of their primary species in value being from a type other than demersal fish.

\section{STEP 5}

We applied the same series of steps to the LE of 2007, on a single shuffle. 12 clusters were identified, which were mostly similar to the 2008 ones (Table 5), with the exception of the Norway pout cluster, which did not appear as the fishery for that species was closed in 2007. The discriminant analysis was conditioned on the 2007 results, and applied to the 2008 LE. The correspondence between the predicted and estimated Level 7 categorisations for 2008 was generally high, with systematically more than $80 \%$ of LE being correctly predicted by the allocation rules.

\section{Discussion}

In summary, we recommend a full sequence to analyse historical catch data and assign them to métier categories, and we synthesise it again below for clearer understanding:

- Select the main species to be retained (Step 1) and run a PCA (Step 2);

- Perform the clustering (Step 3). Depending on the precision scale required and the size of the dataset, we recommend exploring various classifications as done here, to identify the most stable and meaningful patterns. The whole analysis (Steps 1 to 3) can either be performed on a yearly basis if the time trends in métier compositions are to be monitored, or by pooling e.g. the most recent three years of data if a broader overall picture is required.

- Define the most characteristic species of each Level 7 métier obtained, using for example a combination of importance in value, specificity and broad representation across logbooks events. This step includes an element of subjectivity; hence the resulting characterisation of the métiers should be inspected carefully. 
- Characterize each métier to its Level 5 simply by relating each of its characteristic species to its assemblage type (Step 4). The various level 7 métiers of similar assemblages would be aggregated within the corresponding Level 5 métiers, and this would form the basis of the planning of the sampling program for the following year.

- Perform a discriminant analysis on Level 7 métiers to obtain automatic allocation rules (Step 5). Using these rules, any new logbook event entered into the database will be immediately allocated to a métier (both at Levels 7 and 5). Using this approach, the sampling program over the year could be monitored in real-time.

- At the end of the year, perform a complete new statistical analysis of all new logbooks events collected, in order to detect any changes in the métier distribution that may have happened, and if necessary update the sampling program for the forthcoming year..

The definition of clusters of fishing activities is the primary step without which no further analysis can be conducted and no progress in fleet-based or mixed-fisheries management can be achieved. The numerous previous studies addressing métier definition (cited in the introduction) have used different methods on different fisheries. However, none of those studies addressed quantitatively the importance of the choice of the method itself, nor did they implement prediction methods to allocate new logbook events of future years into predefined métiers. While some of these studies were conducted within the framework of the DCF, they typically failed to link explicitly their outcomes with the actual needs and levels defined by the framework. In addition, these previous analyses did not address the issues of national differences at the regional scale. In this regard, we consider that the present analysis is a significant step forward, in that it has succeeded in i) addressing the persistent issue of métier identification in the most objective way, and ii) providing operational and generic open-source tools directly applicable to any regional fisheries where logbook data are routinely available, thus contributing to the practical implementation of the DCF in Europe. In addition, important results were obtained at the regional North Sea level by compiling for the first time a comprehensive international dataset, and the results obtained were clearly different from those obtained applying the same workflow to national data (results not shown); although some clusters here reflect national rather than international fisheries.

With regards to the importance of the methodological choices, it has become clear that different methods returned different classifications. Based on accuracy and robustness of clustering, and the basic knowledge about the fisheries, there was no entirely clear basis for choosing between the CLARA and HAC methods. The results showed many similarities. In both cases, the clusters obtained were mostly meaningful and well balanced in size, especially at the first threshold classification, which returned a broad picture distinguishing major single-species fisheries from main mixed fisheries. The 
second threshold provided finer description of the mixed groups, but results were less robust and some inconsistencies appeared. Both methods required subsetting of the dataset, and sample size appeared to be a determinant factor for improving the robustness of results. However, computation time increased with sampling size. In particular, CLARA computed fairly slowly with large sample size, as the method runs through a loop of increasing kernel number, which slows down the process. In comparison, the K-means method performed quite poorly. Although efficient in computation, the results obtained were largely unstable and often meaningless.

Clustering results were also compared with and without running a PCA in Step 2 (results not shown). Overall, the clusters obtained were fairly similar in average catch composition, but differences were observed in the allocation of some of the LE located at the edges between several clusters in terms of landings profile. Not using a PCA resulted in comparably smaller and more accurately defined clusters for some of the main species but in a bigger pool of less defined groups for other species. Running a PCA decreased significantly the computing time, by reducing the number of explanatory variables, and results were potentially more independent of the choice of number of species retained in Step 1. It appears therefore that the PCA is preferable for describing global trends, but that the exact allocation of some least characteristic individual LE could be challenged.

It is necessary to characterise each cluster with regards to its main species. This step is in itself not as trivial as it sounds, as it requires defining some criteria for selecting the characteristic species. This represented therefore the only part of the whole workflow where subjective choices had to be made. Average value has often been retained as the only criterion. We suggested more detailed empirical rules, based on exploratory analyses of the outcomes and common sense. The list of characteristic species of a cluster included species not only important in average value, but also those which were significantly more abundant in the cluster than in the overall data set, as well as those that were much represented across LE. These criteria and corresponding thresholds are, however, not universal, and any application of this method should pay particular attention to the definition of relevant criteria.

Our results support, but also question some aspects of the DCF of the EU. A number of pan-European workshops (ICES, 2003; EC, 2005, 2006) led to this hierarchical métier definition, and thus the DCF design emerged from intensive (and still ongoing) scientific discussions, where compromises had to be found to reach a "one-size-fits-all" model covering all EU fisheries. In contrast to the DCF Levels 1 to 4 , the Level 5 on target assemblage remains controversial, due to the difficulty of defining and quantifying it accurately. The concept of "target" is by essence very vague when fishers catch a number of species in varying proportions and no information on fishers' intention prior to the fishing operation is routinely collected. With hindsight, the choice of aggregating species by type does not necessarily seem to simplify the establishment of sampling schemes. Fishing does not operate toward a given type but rather toward a given valuable mix of cooccurring species, possibly of different types. The approach leads to the pooling of widely different species caught by distinct métiers together within the same Level 5 assemblage, for example common shrimp and Nephrops, and only the Level 6 categorisation can help to distinguish them - provided that mesh size information is accurately reported in logbooks. Ultimately, Level 7 may actually be preferred to Level 5, by, for example, selecting the first threshold criterion which may not necessarily return a larger number of categories than the current Level 5, but which returns categories that are more appropriate. 


\section{Conclusion}

We have suggested a robust and operational workflow for planning and monitoring DCF sampling programs at Level 5, instead of empirical ordination rules, and we considered métiers at the regional scale by simultaneously analysing catch declarations from different Member States. We believe that the open source programs that were developed for conducting these analyses are extremely powerful in terms of flexibility, general applicability and computing speed. In spite of a fair level of complexity embedded in the computing functions, these programs remain straightforward enough to operate (see scripts and examples of use on http://code.google.com/p/vmstools/wiki/MetiersLogbook), and can be used with any logbook database standardised in the relevant input format. They can also be combined with other similar tools for the analysis of logbook and VMS data (Hintzen et al., in Press). We consider that these tools are directly operational and useful for standardising métier definitions across Europe, and can thus contribute to improved fleet-based and ecosystem-based fisheries management.

\section{Acknowledgments}

This work was funded through the Project "Development of tools for logbook and VMS analysis", Studies for carrying out the Common Fisheries Policy No MARE/2008/10 Lot 2. This support is gratefully acknowledged. We also thank our project partners and colleagues from IFREMER, DTU-Aqua, IMARES, CEFAS and MSS for providing the data necessary for carrying out the analyses. Finally, we are very thankful to Stuart Reeves for his final reading and language improvement.

\section{References}

Bastardie, F., Nielsen, J. R., Ulrich, C., Egekvist, J. and Degel, H. 2010. Detailed mapping of fishing effort and landings by coupling fishing logbooks with satellite-recorded vessel geo-location. Fisheries Research, 106: 41-53.

Beare, D. J. B., Hintzen, N. T., Piet, G. J., Nielsen, J. R., Manco, F., South, A., Bastardie, F., et al. 2011. Development of tools for logbook and VMS data analysis. Studies for carrying out the common fisheries policy. Open call for tenders No MARE/2008/10 Lot 2.

Biseau, A. 1998. Definition of a directed fishing effort in a mixed-species trawl fishery, and its impact on stock assessments. Aquatic Living Resources, 11: 119-136.

Biseau, A., and Gondeaux, E. 1988. Apport des méthodes d'ordination en typologie des flottilles. ICES Journal of Marine Science, 44: 286-296.

Campos, A., Fonseca, P., Fonseca, T., and Parente, J. 2007. Definition of fleet components in the Portuguese bottom trawl fishery. Fisheries Research, 83: 185:191.

Castro, J., Marín, M., Pierce, G.J., and Punzón, A. 2011. Identification of métiers of the Spanish set-longline fleet operating in non-Spanish European waters. Fisheries Research, 102: 184-190.

Castro, J., Punzón, A., Pierce, G.J., Marín, M., and Abad, E. 2010. Identification of métiers of the Northern Spanish coastal bottom pair trawl fleet by using the partitioning method CLARA. Fisheries Research, 102: 184-190. 
Cattell, R. B. 1966. The Scree Test for the Number of Factors. Multivariate Behavioral Research, 1: 245-276.

Duarte, R., Azevedo, M., and Afonso-Dias, M. 2009. Segmentation and fishery characteristics of the mixed-species multi-gear Portuguese fleet. ICES Journal of Marine Science, 66: 594-606.

EC. 2005. Commission Staff Working Paper: Report of the Ad Hoc Meeting of Independent Experts on Fleet-Fishery based Sampling, 23-27 May 2005, Nantes, France. $34 \mathrm{pp}$.

EC. 2006. Commission Staff Working Paper: Report of the Ad Hoc Meeting of Independent Experts on Fleet-Fishery based Sampling, 12-16 June 2006, Nantes, France. 98 pp.

EC. 2008. Commission Decision (2008/949/EC) of 6 November 2008 adopting a multiannual Community programme pursuant to Council Regulation (EC) No 199/2008 establishing a Community framework for the collection, management and use of data in the fisheries sector and support for scientific advice regarding the common fisheries policy Official Journal of the European Union, L 346/37.

EC. 2011. Communication from the Commission to the European Parliament, the Council, the European Economic and Social Committee and the Committee of the Regions. Reform of the Common Fishery Policy. EU COM(2011) 417. 12 pp.

Hartigan, J. A. 1975. Clustering Algorithms. New York: Wiley.

Hartigan, J. A. and Wong, M. A. 1979. A K-means clustering algorithm. Applied Statistics, 28: $100-108$.

He, X., Bigelow, K.A. and Boggs, C. H. 1997. Cluster analysis of longline sets and fishing strategies within the Hawaii-based fishery. Fisheries Research 31: 147-158.

Hintzen, N. T., Bastardie, F., Beare, D. J. B, Piet, G., Ulrich, C., Deporte, N., Egekvist, J., and Degel, $\mathrm{H}$. In press. vmstools: open-source software for the processing, analysis and visualization of fisheries logbook and VMS data. . Accepted in Fisheries Research.

Holley, J.-F., and Marchal, P. 2004. Fishing strategy development under changing conditions: examples from the French offshore fleet fishing in the North Atlantic. ICES Journal of Marine Science, 61: 1410-1431.

ICES. 2003. Report of the Study Group on the Development of Fishery-based Forecasts (SGDFF), 18-21 February 2003, Boulogne, France. ICES Document CM 2003/ACFM:08. $37 \mathrm{pp}$.

ICES. 2010. Report of the Working Group on Mixed Fisheries Advice for the North Sea (WGMIXFISH), 31 August - 3 September 2010, Copenhagen, Denmark. ICES Document CM 2010/ACOM: 35. 93 pp.

Jiménez, M. P., Sobrino, I., and Ramos, F. 2004. Objective methods for defining mixedspecies trawl fisheries in Spanish waters of the Gulf of Cádiz. Fisheries Research, 67: 195-206.

Katsanevakis, S., Maravelias, C. D., and Kell, L. T. 2010. Landings profiles and potential métiers in Greek set longliners. ICES Journal of Marine Science, 67: 646-656. 
Kaufman, L. and Rousseeuw, P. J. 1990. Finding Groups in Data: An introduction to Cluster Analysis. Wiley, New York.

Laurec, A., Biseau, A., and Charuau, A. 1991. Modelling technical interactions. ICES Marine Science Symposia, 193: 225-236.

Lebart, L., Morineau, A., and Piron, M. 1995, Statistique exploratoire multidimensionnelle. Dunod, Paris.

Lewy, P., and Vinther, M. 1994. Identification of Danish North Sea trawl fisheries. ICES Journal of Marine Science, 51: 263-272.

Marchal, P. (Ed). 2006. Technological Developments and tactical adaptations of important EU fleets (TECTAC, $\mathrm{n}^{\circ}$ QLK5-2001-01291). Final report, $651 \mathrm{pp}$ (main report), $369 \mathrm{pp}$ (annexes).

Marchal, P. 2008. A comparative analysis of métiers and catch profiles for some French demersal and pelagic fleets. ICES Journal of Marine Science, 65: 674-686.

Pelletier, D., and Ferraris, J., 2000. A multivariate approach for defining fishing tactics from commercial catch and effort data. Canadian Journal of Fisheries and Aquatic Sciences, 57: 51-65.

Punzón, A., Hernández, C., Abad, E., Castro, J., Pérez, N., and Trujillo, V. 2010. Spanish otter trawl fisheries in the Cantabrian Sea. ICES Journal of Marine Science, 67: 16041616.

R Development Core Team. 2010. R: a language and environment for statistical computing. R Foundation for Statistical Computing, Vienna, Austria. ISBN 3-900051-07-0, http://www.R-project.org.

Rogers, J. B, and Pikitch, E. K. 1992. Numerical definition of groundfish assemblages caught off the coasts of Oregon and Washington using commercial fishing strategies. Canadian Journal of Fisheries and Aquatic Sciences, 49: 2648-2656.

Silva, L., Gil, J., and Sobrino, I. 2002. Definition of fleet components in the Spanish artisanal fishery of the Gulf of Cádiz (SW Spain ICES division IXa). Fisheries Research 59: 117-128.

Tzanatos, E, Dimitriou, E, Katselis, G, Georgiadis, M, and Koutsikopoulos, C. 2005. Composition, temporal dynamics and regional characteristics of small-scale fisheries in Greece Fisheries Research, 73: 147-158.

Tzanatos, E., Somarakis, S., Tserpes, G., and Koutsikopoulos, C. 2006. Identifying and classifying small-scale fisheries métiers in the Mediterranean: a case study in the Patraikos Gulf, Greece. Fisheries Research, 81: 158-168.

Ulrich, C, and Andersen, B. S. 2004. Dynamics of fisheries, and the flexibility of vessel activity in Denmark between 1989 and 2001. ICES Journal of Marine Science, 61:308322.

Ulrich, C., Gascuel, D., Dunn, M., Le Gallic, B. and Dintheer, C. 2001. Estimation of technical interactions due to the competition for resource in a mixed-species fishery, and 
the typology of fleets and métiers in the English Channel. Aquatic Living Resources, 14: 267-281.

Ulrich, C., Wilson, D. C., Nielsen, J. R., and Reeves, S. A. 2009. Potentials and challenges in fleet- and métier- based approaches for fisheries management in the CFP. ICES Document CM 2009/R: 06.

Ward, J. H. 1963. Hierarchical grouping to optimize an objective function. Journal of the American Statistical Association, 58: 236-244.

\section{Tables}

\begin{tabular}{|c|c|c|c|}
\hline FAO CODE & Scientific name & English name & DCF Level 5 \\
\hline $\mathrm{BIB}$ & Trisopterus luscus & Bib & DEF \\
\hline BRB & Spondyliosoma cantharus & Black seabream & DEF \\
\hline BSS & Dicentrarchus labrax & European seabass & DEF \\
\hline COD & Gadus morhua & Atlantic cod & DEF \\
\hline $\mathrm{CSH}$ & Crangon crangon & Common shrimp & CRU \\
\hline СТС & Sepia officinalis & Common cuttlefish & CEP \\
\hline GUU & Chelidonichthys lucerna & Tub gurnard & DEF \\
\hline HAD & Melanogrammus aeglefinus & Haddock & DEF \\
\hline HER & Clupea harengus & Atlantic herring & SPF \\
\hline HKE & Merluccius merluccius & European hake & DEF \\
\hline LEM & Microstomus kitt & Lemon sole & DEF \\
\hline MAC & Scomber scombrus & Atlantic mackerel & SPF \\
\hline MEG & Lepidorhombus whiffiagonis & Megrim & DEF \\
\hline MON & Lophius piscatorius & Monkfish & DEF \\
\hline MUR & Mullus surmuletus & Surmullet & DEF \\
\hline NEP & Nephrops norvegicus & Norway lobster & CRU \\
\hline NOP & Trisopterus esmarkii & Norway pout & DEF \\
\hline PLE & Pleuronectes platessa & European plaice & DEF \\
\hline POK & Pollachius virens & Saithe & DEF \\
\hline POL & Pollachius pollachius & Pollack & DEF \\
\hline PRA & Pandalus borealis & Northern prawn & CRU \\
\hline RAJ & Rajidae & Rays and skates nei & DEF \\
\hline SAN & Ammodytes spp & Sandeels nei & DEF \\
\hline SDV & Mustelus spp & Smooth-hounds nei & DEF \\
\hline SOL & Solea solea & Common sole & DEF \\
\hline SPR & Sprattus sprattus & European sprat & SPF \\
\hline SQU & Loliginidae, Ommastrephidae & Various squids nei & CEP \\
\hline SYC & Scyliorhinus canicula & Small-spotted catshark & DEF \\
\hline TUR & Psetta maxima & Turbot & DEF \\
\hline WHG & Merlangius merlangus & Whiting & DEF \\
\hline WIT & Glyptocephalus cynoglossus & Witch flounder & DEF \\
\hline
\end{tabular}

Table 1. Species name, FAO code and corresponding DCF Level 5 for the main species retained in 2008 (DEF= demersal fish, CRU=crustacean, CEP=cephalopod, SPF=small pelagic fish). Only the 31 out of the 58 retained species that are named in the article are displayed. 


\begin{tabular}{|c|c|c|c|c|c|c|}
\hline \multirow{3}{*}{$\frac{\text { Criterion }}{\text { First threshold }}$} & & & \multicolumn{4}{|c|}{ Sample size } \\
\hline & \multicolumn{2}{|c|}{ Method } & $1 \%$ & \multirow{2}{*}{$\frac{5 \%}{1.6}$} & \multirow{2}{*}{$\frac{10 \%}{2.7}$} & \multirow{2}{*}{$\frac{30 \%}{12.5}$} \\
\hline & HAC & Computing time & 1.2 & & & \\
\hline & & Shuffle 1 & $7(18.9)$ & $8(20.6)$ & $8(21.2)$ & $8(20.6)$ \\
\hline & & Shuffle 2 & $7(18.8)$ & $8(21.0)$ & $7(18.7)$ & $8(20.8)$ \\
\hline & & Shuffle 3 & $6(15.4)$ & $9(23.1)$ & $8(21.4)$ & $8(20.6)$ \\
\hline & CLARA & Computing time & 1.22 & 11.74 & 31.62 & \\
\hline & & Shuffle 1 & $7(19.2)$ & $8(21.5)$ & $6(16.7)$ & \\
\hline & & Shuffle 2 & $7(19.0)$ & $7(19.0)$ & $6(16.6)$ & \\
\hline & & Shuffle 3 & $6(16.6)$ & $6(16.1)$ & $6(16.1)$ & \\
\hline & $K$-means & Computing time & & & & \\
\hline & & Shuffle 1 & & & & \\
\hline & & Shuffle 2 & & & & \\
\hline & & Shuffle 3 & & & & \\
\hline \multirow[t]{12}{*}{ Second threshold } & HAC & Computing time & 1.3 & 1.7 & 2.7 & 11.9 \\
\hline & & Shuffle 1 & $10(25.5)$ & $9(23.0)$ & $10(24)$ & $12(28.3)$ \\
\hline & & Shuffle 2 & $9(22.4)$ & $9(23.6)$ & $9(23.6)$ & $11(27.1)$ \\
\hline & & Shuffle 3 & $8(19.5)$ & $11(25.6)$ & $12(28.0)$ & $9(23.3)$ \\
\hline & CLARA & Computing time & 1.79 & 35.35 & 194 & \\
\hline & & Shuffle 1 & $7(18.6)$ & $14(32.5)$ & $13(30.2)$ & \\
\hline & & Shuffle 2 & $15(33.7)$ & $14(32.5)$ & $14(32.6)$ & \\
\hline & & Shuffle 3 & $10(24.4)$ & $13(30.2)$ & $16(36.1)$ & \\
\hline & $K$-means & Computing time & \multicolumn{4}{|c|}{4.8} \\
\hline & & Shuffle 1 & \multicolumn{4}{|c|}{$11(27.2)$} \\
\hline & & Shuffle 2 & \multicolumn{4}{|c|}{$14(32.3)$} \\
\hline & & Shuffle 3 & \multicolumn{4}{|c|}{$12(29.3)$} \\
\hline
\end{tabular}

Table 2. Performance and outcomes of the three clustering methods for two levels of classification, three shuffled datasets and four sample sizes (HAC and CLARA methods only). Average computing time (minutes), resulting number of clusters and clustering variance ratio (in \%). 


\begin{tabular}{|c|c|c|c|c|c|c|}
\hline \multirow[b]{2}{*}{ Cluster number } & \multirow[b]{2}{*}{ Level 7} & \multirow[b]{2}{*}{ Level 5} & \multicolumn{2}{|c|}{ First threshold } & \multicolumn{2}{|c|}{ Second threshold } \\
\hline & & & HAC & CLARA & HAC & CLARA \\
\hline 1 & OTB Nephrops & CRU & NEP $(85,100)$ & $\operatorname{NEP}(79,91)$ & NEP $(84,100)$ & $\operatorname{NEP}(94,100)$ \\
\hline 2 & $\begin{array}{l}\text { OTB Nephrops - } \\
\text { monkfish }\end{array}$ & $M C D$ & & & & $\begin{array}{l}\text { NEP }(61,94) \\
\text { MON }(12,77)\end{array}$ \\
\hline 14 & $\begin{array}{l}\text { OTB Northern } \\
\text { prawn }\end{array}$ & CRU & PRA $(50,59)$ & & PRA $(88,100)$ & PRA $(89,100)$ \\
\hline 8 & OTB shrimp & CRU & CSH $(100,100)$ & & $\mathrm{CSH}(100,100)$ & $\mathrm{CSH}(100,100)$ \\
\hline 5 & $\begin{array}{l}\text { OTB cod- } \\
\text { haddock }\end{array}$ & DEF & $\begin{array}{l}\operatorname{COD}(21,79) \\
\operatorname{MON}(21,66)\end{array}$ & $\begin{array}{l}\operatorname{MON}(20,69) \\
\operatorname{COD}(19,77)\end{array}$ & $\begin{array}{l}\operatorname{COD}(25,82) \\
\operatorname{POK}(19,69)\end{array}$ & $\begin{array}{l}\operatorname{COD}(39,88) \\
\operatorname{HAD}(24,71)\end{array}$ \\
\hline 9 & OTB saithe - hake & DEF & HAD $(12,70)$ & HAD $(11,69)$ & $\begin{array}{l}\text { HAD }(14,67) \\
\text { MON }(13,57)\end{array}$ & $\begin{array}{l}\text { POK }(39,90) \\
\text { HKE }(8,63)\end{array}$ \\
\hline 6 & $\begin{array}{l}\text { OTB monkfish- } \\
\text { megrim }\end{array}$ & DEF & & & $\begin{array}{l}\operatorname{MON}(53,98) \\
\operatorname{MEG}(13,73)\end{array}$ & $\begin{array}{l}\text { MON }(48,98) \\
\operatorname{MEG}(9,60)\end{array}$ \\
\hline 3 & $\begin{array}{l}\text { OTB squid - } \\
\text { whiting }\end{array}$ & MCF & $\begin{array}{l}\text { SQU }(22,69) \\
\text { WHG }(13,66) \\
\text { MUR }(9,62) \\
\text { BSS }(8,52)\end{array}$ & $\begin{array}{l}\text { SQU }(24,74) \\
\text { WHG }(15,69) \\
\text { MUR }(10,67) \\
\text { BSS }(9,55)\end{array}$ & $\begin{array}{l}\operatorname{SQU}(35,71) \\
\text { WHG }(22,73) \\
\text { MAC }(8,52)\end{array}$ & $\begin{array}{l}\text { SQU }(39,83) \\
\text { WHG }(23,79) \\
\text { MUR }(6,60) \\
\operatorname{MAC}(6,55)\end{array}$ \\
\hline 13 & OTB sea bass & DEF & $\begin{array}{l}\text { CTC }(7,47) \\
\text { BIB }(2,60)\end{array}$ & $\begin{array}{l}\text { CTC }(7,50) \\
\operatorname{BIB}(2,64) \\
\text { GUU }(2,60)\end{array}$ & $\begin{array}{l}\text { BSS }(15,65) \\
\text { MUR }(14,74) \\
\text { CTC }(13,65) \\
\text { BRB }(5,57) \\
\text { BIB }(3,70)\end{array}$ & $\begin{array}{l}\text { BSS }(24,78) \\
\text { BRB }(10,75) \\
\text { RAJ }(9,75) \\
\operatorname{SDV}(5,67) \\
\operatorname{SYC}(3,78)\end{array}$ \\
\hline 7 & $\begin{array}{l}\text { OTB cuttlefish- } \\
\text { surmullet }\end{array}$ & MCF & & & & $\begin{array}{l}\text { CTC }(31,86) \\
\operatorname{MUR}(27,90) \\
\operatorname{GUU}(4,73)\end{array}$ \\
\hline 4 & $\begin{array}{l}\text { OTB plaice- } \\
\text { lemon sole }\end{array}$ & DEF & $\begin{array}{l}\text { PLE }(49,95) \\
\text { LEM }(13,51) \\
\text { TUR }(10,55)\end{array}$ & $\begin{array}{l}\text { PLE }(53,96) \\
\text { LEM }(14,52) \\
\text { TUR }(9,51)\end{array}$ & $\begin{array}{l}\operatorname{PLE}(49,95) \\
\operatorname{LEM}(13,51) \\
\operatorname{TUR}(10,55)\end{array}$ & $\begin{array}{l}\operatorname{PLE}(54,97) \\
\text { LEM }(14,52) \\
\text { TUR }(9,52)\end{array}$ \\
\hline 11 & OTB sole & DEF & SOL $(75,99)$ & SOL $(66,94)$ & SOL $(75,99)$ & SOL $(68,95)$ \\
\hline 10 & OTB sandeel & DEF & $\operatorname{SAN}(99,100)$ & SAN $(99,100)$ & SAN $(99,100)$ & SAN $(99,100)$ \\
\hline 12 & $\begin{array}{l}\text { OTB Norway } \\
\text { pout }\end{array}$ & DEF & & & $\begin{array}{l}\text { NOP }(29,32) \\
\text { HER }(17,58)\end{array}$ & NOP $(95,100)$ \\
\hline
\end{tabular}

Results were obtained with the shuffle 2 dataset, using a 10\% sample size for CLARA and a $30 \%$ sample size for HAC. The horizontal lines indicate how the clusters overlap with each other across the four classifications. Cluster numbers are the arbitrary ranking of classification outputs and are only retained for the description of Figures 4 and 5.

Table 3. Identification of the métiers at Level 7 and corresponding Level 5 , and comparison of the corresponding clusters obtained with HAC and CLARA at both first and second threshold, indicating for each cluster the list of characteristic species, and for each of these, the mean landings percentage in value and the percentage of logbook events capturing it, respectively. Results obtained with the shuffle 2 dataset, using $10 \%$ sample 
size for CLARA and 30\% sample size for HAC. The horizontal lines indicate how the clusters overlap with each other across the four classifications. Cluster numbers are the arbitrary ranking of classification's outputs and are only retained for the description of Figures 4 and 5.

\begin{tabular}{lcccc}
\hline & \multicolumn{4}{c}{ CLARA } \\
\cline { 2 - 5 } Criterion & CRU & MCD & MCF & DEF \\
\hline First species & - & - & 52 & 1 \\
CEP & 100 & 93 & - & 5 \\
CRU & - & 5 & 43 & 93 \\
DEF & - & 2 & 5 & 1 \\
SPF & - & - & 38 & - \\
First group & 100 & 82 & - & 2 \\
CEP & - & 16 & 59 & 97 \\
CRU & - & 2 & 3 & 1 \\
DEF & & & & \\
SPF & & & & \\
\hline
\end{tabular}

Table 4. Percentage of correspondence between métiers defined by the CLARA algorithm aggregated at Level 5 (in columns) with the métiers defined by the "First Species" and "First Group" ordination methods (in rows). 


\begin{tabular}{|c|c|c|c|c|c|c|c|c|c|c|c|c|c|c|}
\hline Level 7 & NEP & PRA & CSH & $\begin{array}{l}\text { COD - } \\
\text { HAD }\end{array}$ & $\begin{array}{c}\text { MON - } \\
\text { POK }\end{array}$ & $\begin{array}{l}\text { SQU - } \\
\text { WHG }\end{array}$ & $\begin{array}{c}\text { BSS - } \\
\text { BRB }\end{array}$ & $\begin{array}{c}\text { MUR - } \\
\text { CTC }\end{array}$ & $\begin{array}{c}\text { PLE - } \\
\text { LEM }\end{array}$ & SOL & SAN & $\begin{array}{c}\text { SPR - } \\
\text { HER }\end{array}$ & $\begin{array}{l}\text { Non } \\
\text { alloc. }\end{array}$ & Total \\
\hline$\overline{\text { NEP }}$ & 99.8 & & & & & & & & & 0.1 & & & & 24865 \\
\hline NEP - MON & 82.3 & & & 3.9 & 9.5 & 0.3 & 0.3 & & 0.6 & 0.4 & & 2.4 & 0.2 & 14252 \\
\hline PRA & & 100 & & & & & & & & & & & & 1527 \\
\hline $\mathrm{CSH}$ & & & 100 & & & & & & & & & & & 1513 \\
\hline COD - HAD & 0.2 & & & 89.5 & 5.0 & 1.0 & 3.5 & & 0.5 & 0.2 & & & 0.1 & 7040 \\
\hline POK - HKE & 4.1 & 0.3 & & 11.6 & 83.5 & & & & 0.3 & & & & & 5757 \\
\hline MON - MEG & 2.5 & & & 4.2 & 92.9 & 0.2 & & & 0.2 & & & & & 5919 \\
\hline SQU - WHG & & & & 2.3 & & 88.2 & 3.2 & 3.4 & & 25 & & 0.2 & & 8070 \\
\hline BSS - BRB & & & & 1.4 & 0.2 & 3.9 & 90.4 & 2.7 & 0.3 & 1.0 & & & & 3680 \\
\hline CTC - MUR & & & & & & 11.5 & 0.5 & 86.6 & 0.3 & 1.0 & & & & 2903 \\
\hline PLE - LEM & 1.6 & & & 2.7 & & 1.7 & 0.1 & 0.2 & 92.8 & 0.9 & & & & 8702 \\
\hline SOL & 1.6 & & & 1.6 & & 0.4 & 0.3 & 0.2 & 0.8 & 95.0 & & & & 9289 \\
\hline SAN & & & & & & & & & & & 99.5 & 0.5 & & 2877 \\
\hline NOP & & & & 8.2 & 6.3 & 1.9 & & & & & & 83.5 & & 364 \\
\hline Total & 37248 & 1548 & 1513 & 8418 & 12037 & 7922 & 3930 & 2935 & 8349 & 9264 & 2865 & 685 & 44 & 96758 \\
\hline
\end{tabular}

Table 5. Correspondence between the 2008 clusters defined by cluster analysis (in rows) with the 2008 clusters predicted by discriminant analysis applied on the 2007 clusters (in columns), expressed in percentage of number of LE by row, and total number of LE in each class. 


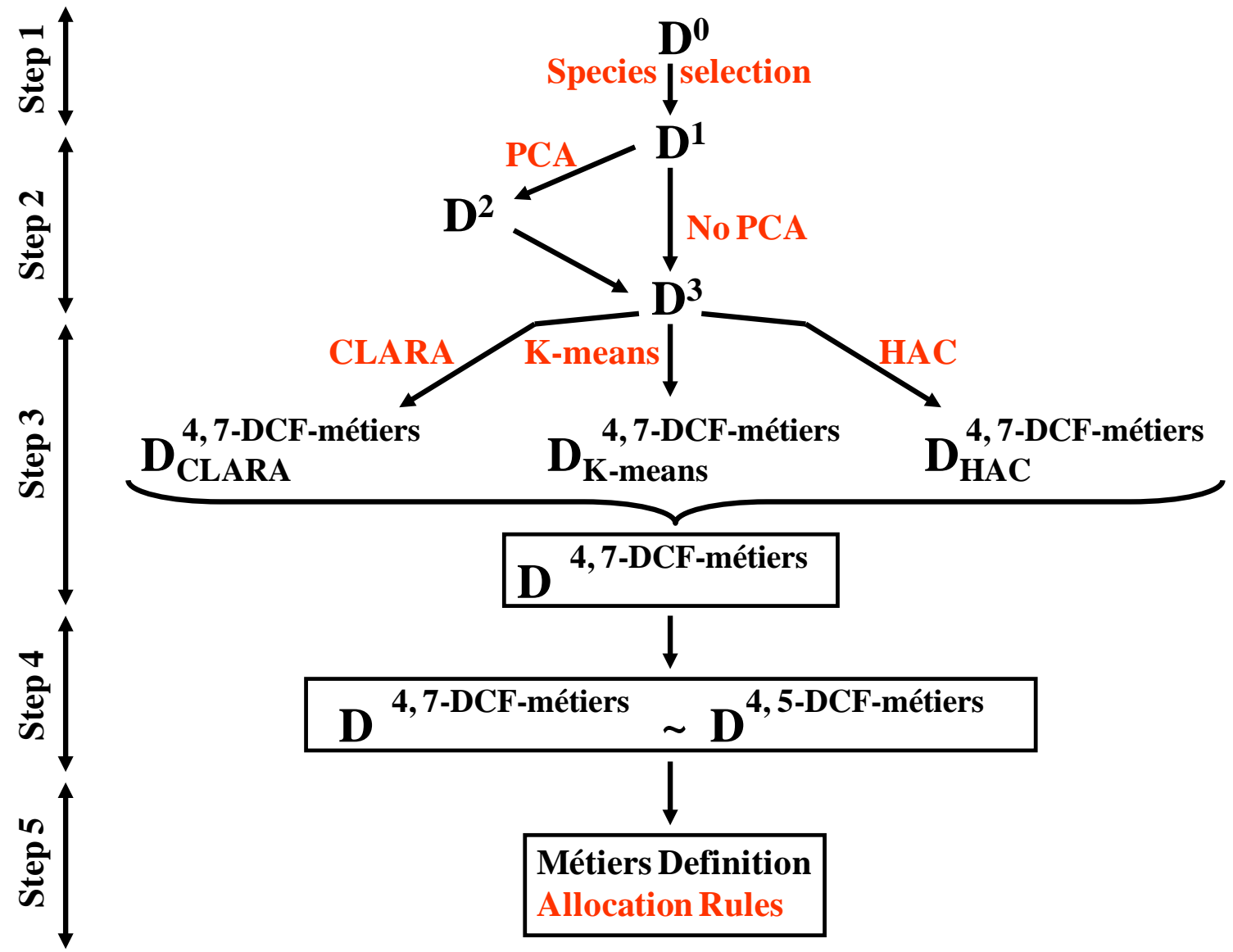

Figure 1. Workflow of the analyses for the definition of métiers using catch profiles and the definition of the allocation rules of a logbook event to a métier. Symbols are explained in the text. 


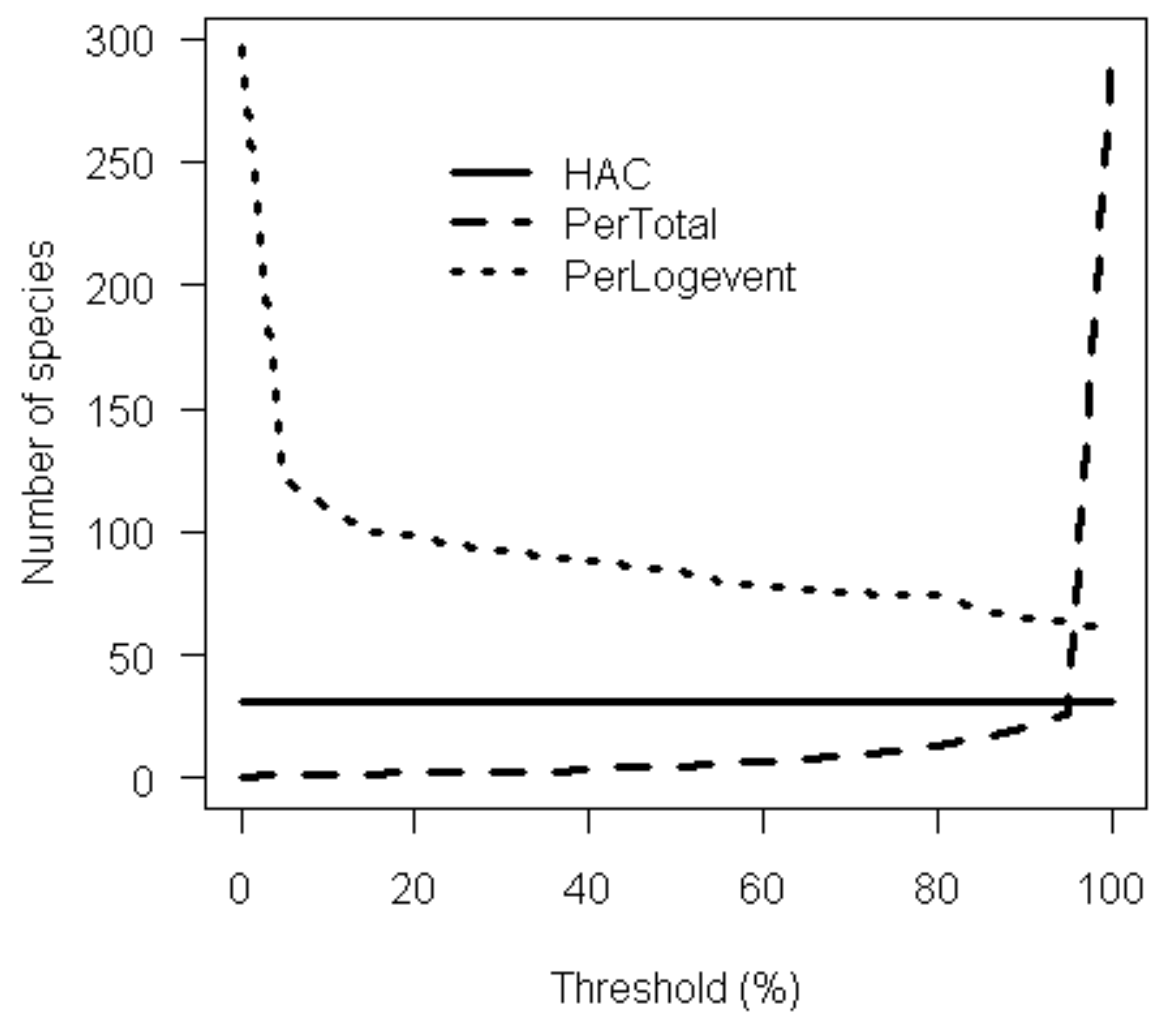

Figure 2. Number of main species selected depending on the method and threshold chosen. 

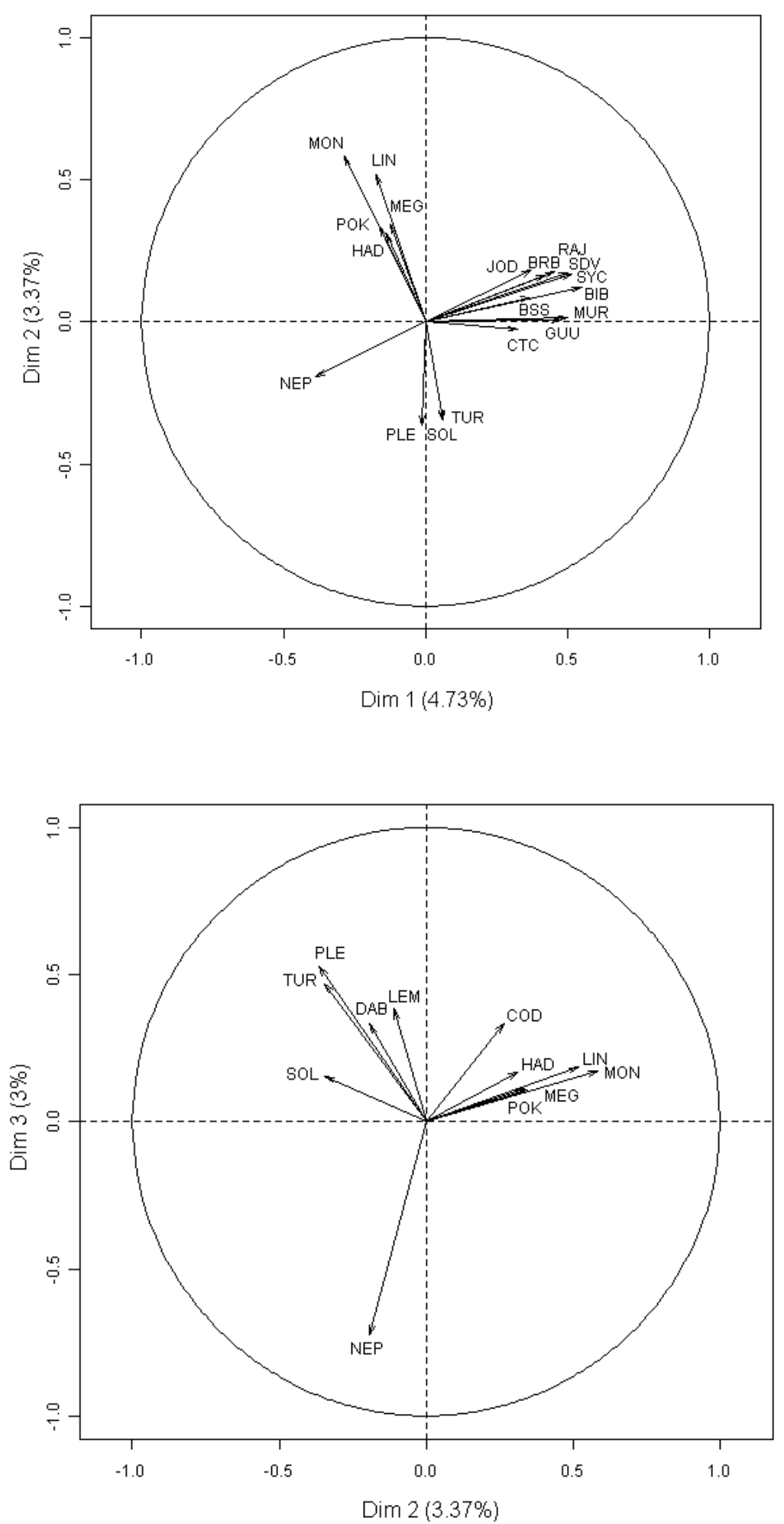

Figure 3. PCA projection of the species on axes 1 and 2 (left) and 2 and 3 (right). Percentage number on axes labels gives the percentage of inertia explained by the axis. 

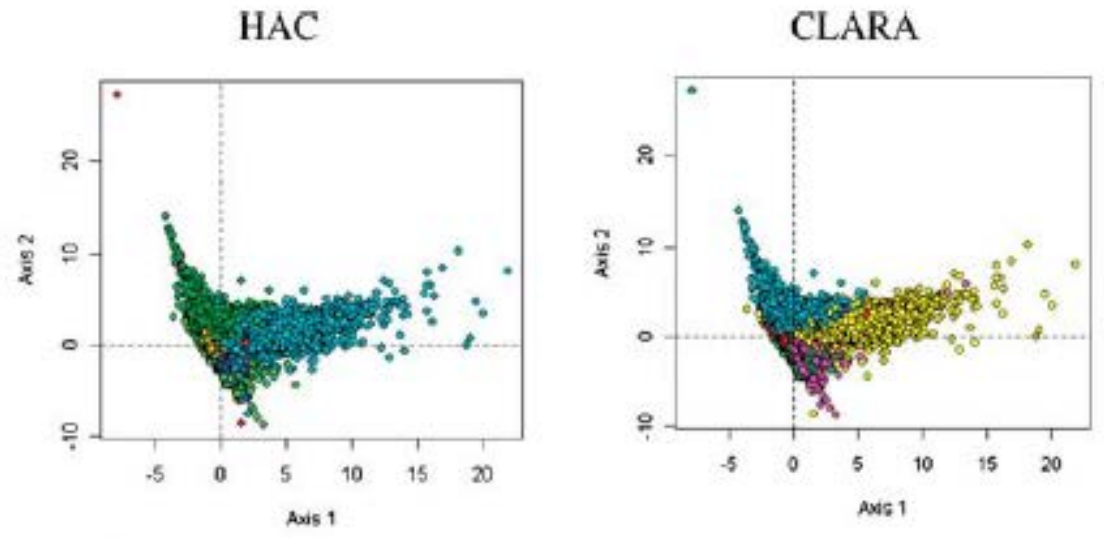

First

threshold
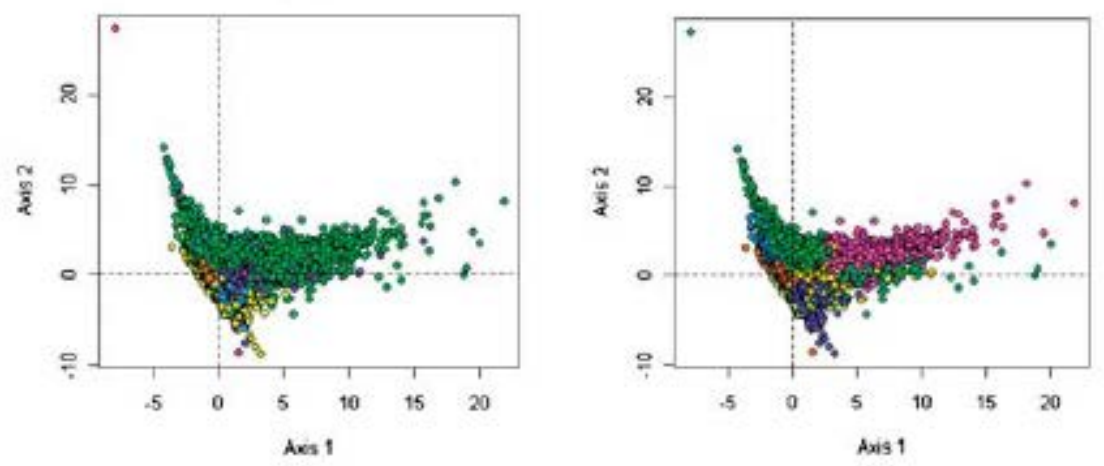

Second

threshold

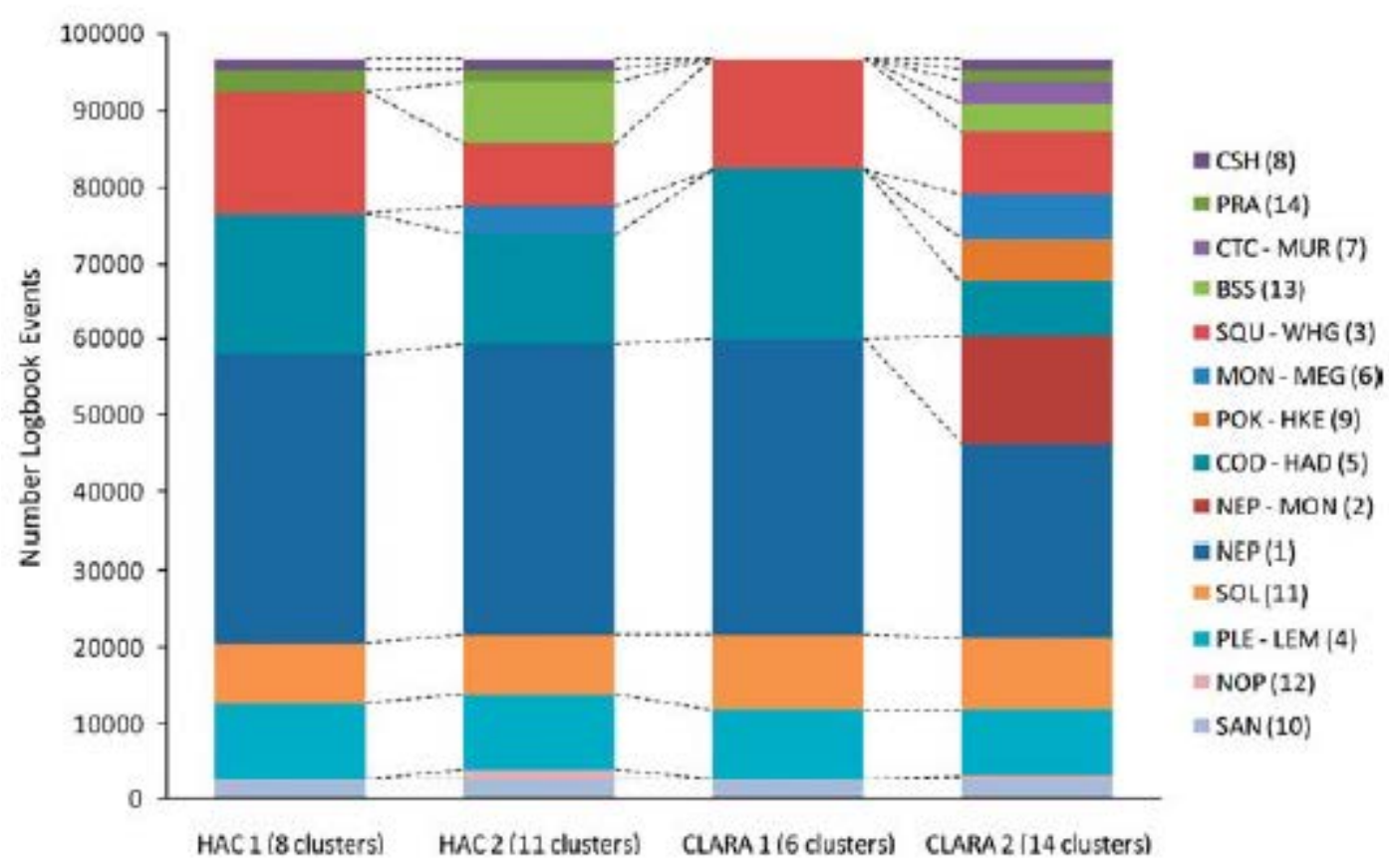

Figure 4. Top: Projection of logbook events in the subspace of the two first axes for the clustering methods HAC and CLARA and at two threshold levels. Each identified cluster is colored. Bottom: Number of logbook events (LE) by Level 7 obtained with HAC and CLARA at both first and second threshold. The horizontal lines indicate how the clusters overlap with each other across the four classifications. Results obtained with the shuffle 2 dataset, using 10\% sample size for CLARA and 30\% sample size for HAC. In brackets in the legend are the clusters numbers in the order they appear in the output (see also Table 3 and Figure 5). [FIGURE IN COLOR] 


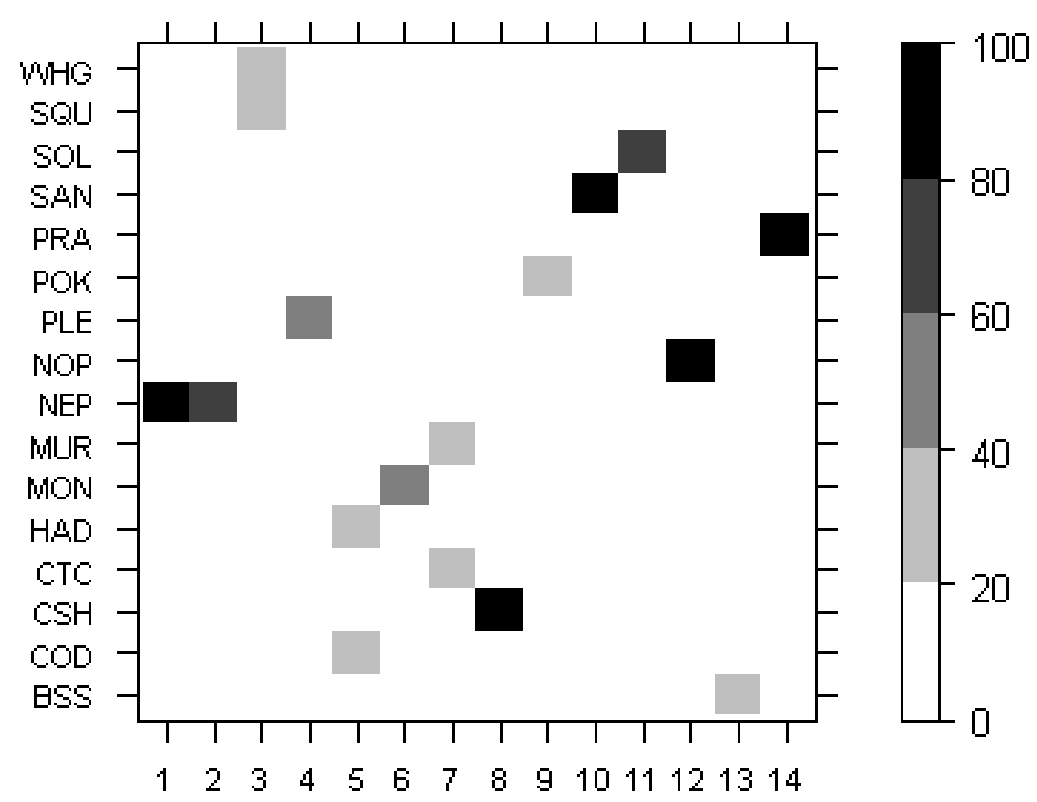

Figure 5. Percentage of cash value per species per cluster. Only species with value larger than $20 \%$ within at least one cluster are displayed. Results obtained with the shuffle 2 dataset, using $10 \%$ sampling size and CLARA method. Clusters' numbers on horizontal axis correspond to numbers from the Table 3. 